\title{
Study on the Combined Performance of Fiber Reinforce Concrete Material
}

\author{
Zeng Siyi ${ }^{1}$, Jiang Guoping ${ }^{2, *}$ and Xiao Sanxia ${ }^{2}$ \\ ${ }^{1}$ Earthquake Engineering Research Test Center, Guangzhou University, Guangzhou 510405, China \\ ${ }^{2}$ School of Engineering, 2011 High Performance Concrete Coordination Center in Fujian Province, Fujian Jiangxia \\ University, Fuzhou, Fujian 350108, China
}

\begin{abstract}
As concrete is a heterogeneous material. There is a combination of weak interface - interface in the concrete. From the point of view of mechanics analysis, the interface exists in the combination of materials within the boundary [1]. For ordinary concrete, damage often occurs from the junction interface. The analysis of concrete materials and its stress distribution near the interface has vital significance. In fact, the boundary condition on the interface, and mutual constraint represent the deformation of the fiber and concrete. The constraints cause stress concentration of interface and nearby interface geometry mutations where stress concentration is very serious. In the elastic range, the stress point at some point tends to infinity, called a singularity. At the same time, due to material composition by multiphase materials, there are a lot of micro cracks at the interfaces. The study of the interface crack model and the materials of the singularity has an important means for the material's performance.
\end{abstract}

Keywords: Concrete, crack, earthquake, fiber.

\section{INTRODUCTION}

Concrete is suitable for bridge decks, thin shell structures, nuclear power plants and defensive facilities that may experience impact loads such as earthquake and blast loading. But the higher the strength of the concrete, the more brittle it is [1-3]. Understanding the strain rate effect is very important in assessing the structural capacity in resisting impact and blast loads. It is well known that using small amount of steel fibers into concrete will enhance the tensile and fatigue resistance and toughness of concrete. Although the mechanical properties of steel fiber reinforced concrete have been investigated intensively, and widely used in engineering, most of these investigations and applications were only limited to the static and dynamic case [4-6]. The study on the combined performance of fiber reinforce concrete material had not been carried out. In this paper, combined performance of fiber reinforce concrete is studied. Pointer to the combined performance is obtained.

\subsection{Dundur Parameters}

For composite materials such as fiber reinforced concrete, there are two important combinations of elastic parameters - Dundurs parameters:

*Address correspondence to this author at the School of Engineering, 2011 High Performance Concrete Coordination Center in Fujian Province, Fujian Jiangxia University, Fuzhou, Fujian 350108, China; E-mail: ip2002999@126.com

$$
\begin{gathered}
\alpha=\frac{\mu_{1}\left(k_{2}+1\right)-\mu_{2}\left(k_{1}+1\right)}{\mu_{1}\left(k_{2}+1\right)+\mu_{2}\left(k_{1}+1\right)} \\
\beta=\frac{\mu_{1}\left(k_{2}-1\right)-\mu_{2}\left(k_{1}-1\right)}{\mu_{1}\left(k_{2}-1\right)+\mu_{2}\left(k_{1}-1\right)}
\end{gathered}
$$

Where $\mu=\frac{E}{2(1+v)} ; k=\frac{3-v}{1+v}$ in the plane stress problem, $k=3-4 v$ in the plane strain problem, $\mu=\frac{E}{2(1+v)}, v$ is the Poisson's ratio.

The Goursat equations are:

$$
\begin{aligned}
& \sigma_{y}+i t_{x y}=\xi^{\prime}+\overline{\xi^{\prime}}+\bar{z} \zeta^{\prime \prime}+\zeta^{\prime} \\
& \sigma_{y}-i t_{x y}=\xi^{\prime}+\overline{\xi^{\prime}}-\bar{z} \zeta^{\prime \prime}-\zeta^{\prime} \\
& 2 \mu(\mu+i v)=k \xi-z \overline{\xi^{\prime}}-\bar{\zeta}
\end{aligned}
$$

According to the Dundurs solutions, we can obtain the following equations:

$$
\xi_{1}=\frac{1+\beta}{1-\alpha} \xi_{2}+\frac{\beta-\alpha}{1-\alpha}\left(z \bar{\xi}_{2}^{\prime}+\bar{\zeta}_{2}\right)
$$


$z \bar{\xi}_{1}^{\prime}+\bar{\zeta}_{1}=-\frac{1+\beta}{1-\alpha} \xi_{2}+\frac{\beta-\alpha}{1-\alpha}\left(z \bar{\xi}_{2}^{\prime}+\bar{\zeta}_{2}\right)$

Dundur parameter actually gives the interface constraints of the composite material and the influence of material properties. Concrete is a kind of composite materials, substrate material and aggregate in concrete interface. The fiber and matrix material interface is a weak link, taking the Dundur parameters into consideration for the fiber reinforced concrete which is the foundation for singularity characteristics at the interface of the fiber reinforced concrete [2].

\subsection{Fiber Enhanced Model of Concrete Material}

Studying the micro cracks in the concrete material model, in fact, the focus on the research is singular in the interface crack. However, the role of adding fiber concrete is mainly a strengthening and toughening effect. It is necessary to study the role of fiber in the substrate concrete.

There are some models can be used to study the combined performance of fiber reinforce concrete.

\section{Model 1:}

Research problems of single fiber based mechanical model are shown in Fig. (1), with cracks and fiber in total plus under the action of stress field. To simplify, only plane strain or strain is considered. This paper only considers I type crack problem. We assume that an absence of fiber plus I type caused by stress field in crack tip stress intensity factor for K0. Due to the role of the fiber, near crack tip stress intensity factor of the change, $\mathrm{K} 1$ is used. $\Delta K=K_{1}-K_{0}$ can be used to describe the toughness role of the fiber. If $\Delta K<0$, fiber on the crack tip field is shielded (toughness).

For this crack in the substrate material in the model [8], we can obtain:

$$
\Delta K=\frac{K_{0}}{\pi} \int_{A} r^{-2}\left(C_{1} \cos \frac{\theta}{2} \cos \frac{3 \theta}{2}+C_{2} \cos \theta \sin ^{2} \theta\right) d A
$$

Where

$$
\begin{aligned}
& C_{1}=\frac{(1-\alpha)(1-2 \mu)}{1+\alpha-2 \mu} \\
& C_{2}=\frac{3(1-\alpha)}{2(1+3 \alpha-4 \mu \alpha)} \\
& \alpha=\frac{E_{x}}{E_{h}}
\end{aligned}
$$

Among them, $E_{x}$ is for the elastic modulus of fiber, and $E_{h}$ is for concrete elastic modulus of matrix.

\section{Model 2:}

Research problems of fiber based mechanical model are shown in Fig. (2). At this point, the crack and fiber are still under the action of stress $\left(\sigma_{0}\right)$ field. To simplify, only plane strain or strain problem is considered.

For solving the conversion (Fig. (2b) of the three layer

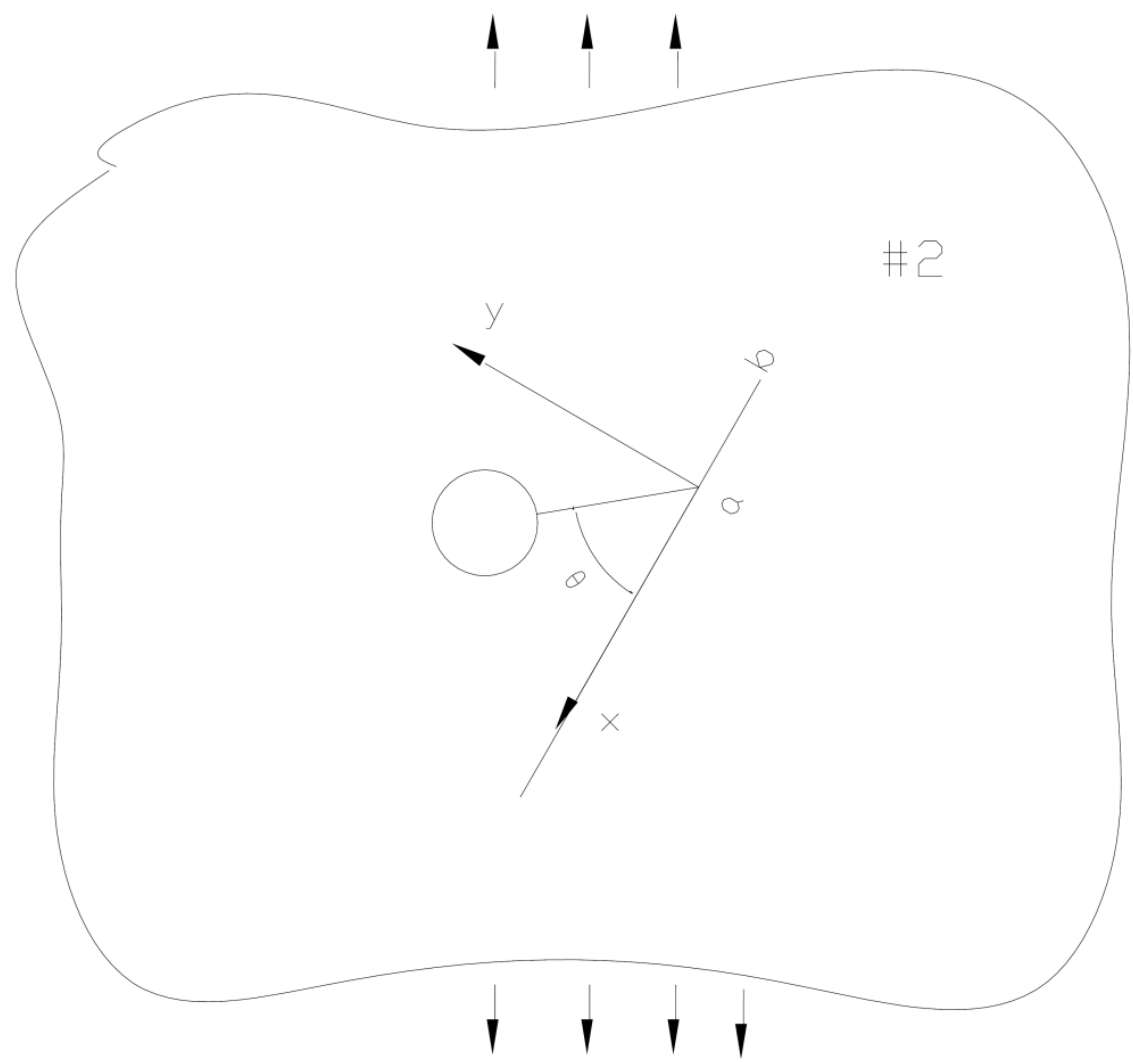

Fig. (1). Single fiber based crack model of concrete. 


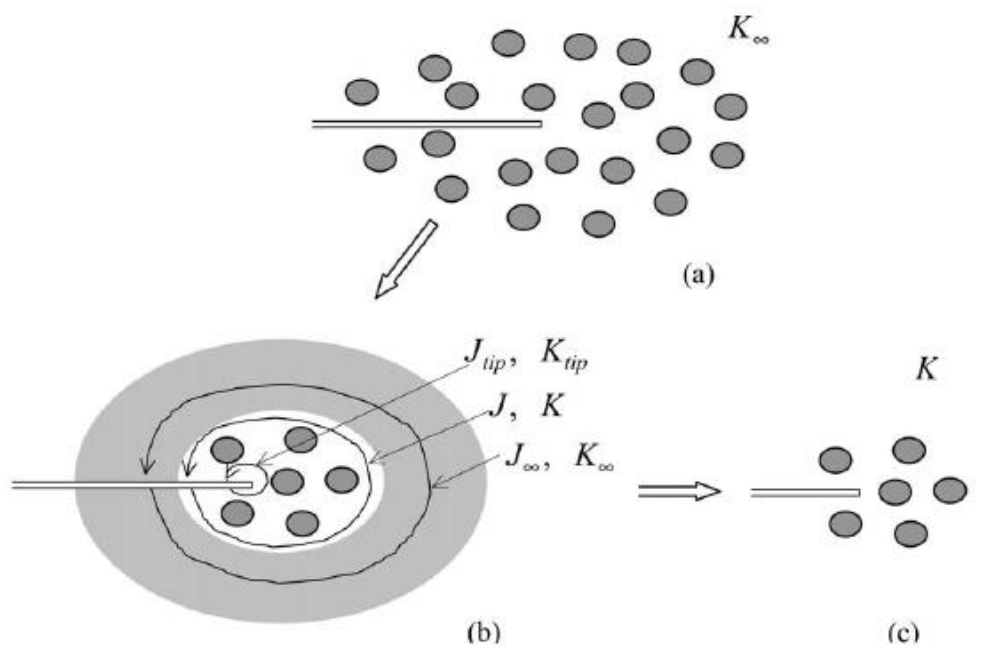

Fig. (2). Much fiber based crack model of concrete.

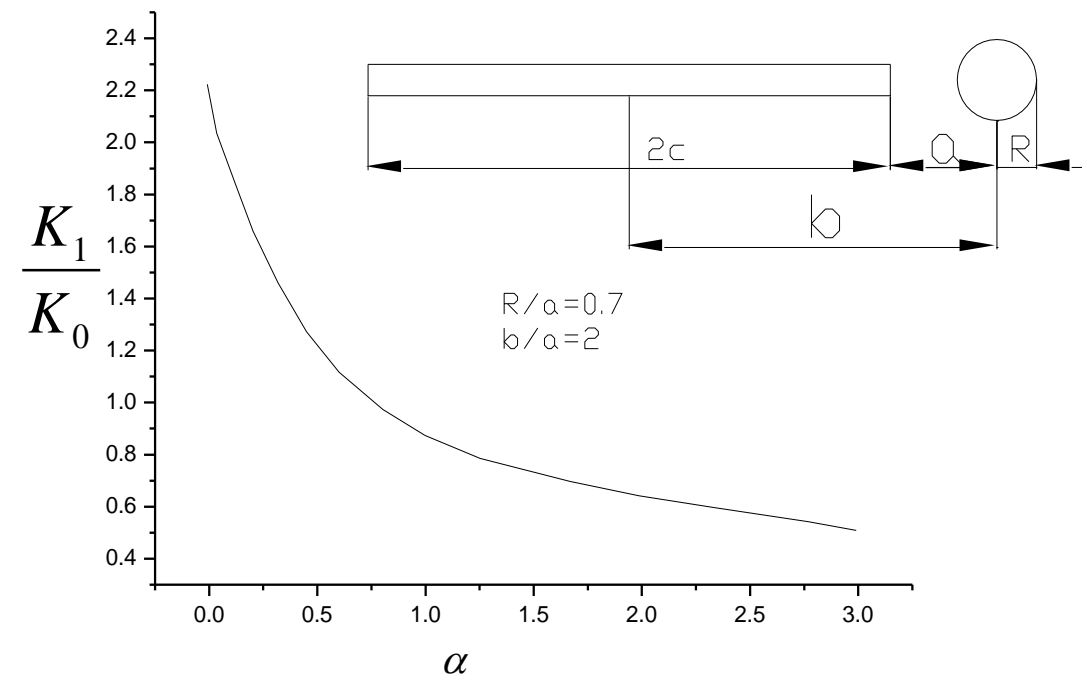

Fig. (3). The relationship between the $\frac{K_{1}}{K_{0}}$ and $\alpha$.

model), the first layer is of fiber, the second is the concrete substrate, and the third layer is of fiber composite concrete materials. We thus obtain:

$$
\frac{K_{1}}{K_{0}}=\sqrt{\alpha_{2}}\left[1+\frac{1}{\pi} \int_{A} r^{-2}\left(C_{1} \cos \frac{\theta}{2} \cos \frac{3 \theta}{2}+C_{2} \cos \theta \sin ^{2} \theta\right) d A\right](9)
$$

Defining $\alpha_{2}$ as the ratio of the elastic modulus between the concrete matrix and the fiber. For single fiber, it can be thought that the second and third layer materials are consistent. Then eq. 2 degradation for eq. 1 is:

So in specific conditions, we can solve the eq. 1 with numerical calculation. The relationship between the $\frac{K_{1}}{K_{0}}$ and $\alpha$ can be obtained and we can discuss the behavior of the strengthening and toughening effect. With reference to the literature, the specific parameters and the relation curves are all obtained (Fig. 3).

\section{CONCLUSION}

Eq.1 describes the role of toughening for single fiber. Much fiber based crack model of concrete is also given in this paper. The single model of toughening pointer can be obtained from the much fiber based crack model. In the distance close to the fiber, toughening effect is good.

2 From Fig. (3), we can see that steel fiber and other hard fiber can join the hard substrate material (concrete grade is high) in the concrete, and soft fibers such as polypropylene fiber can generally add soft substrate material in the concrete (concrete grade is low).

\section{CONFLICT OF INTEREST}

The authors confirm that this article content has no conflict of interest. 


\section{ACKNOWLEDGEMENTS}

This study was supported by the China Postdoctoral Science Foundation (2013M540776), The Guangzhou city association for science and technology projects (2013SX014 and 2013SX022); Housing and Urban-Rural tion Bureau (2012-k4-17); High performance concrete coordination center in Fujian province.

\section{REFERENCES}

[1] K. Wu, "Effect of metallic aggregateon strength and fracture properties of HPC", Cement and Concrete Research, vol. 31, pp. 113-118, June 2001.

[2] A. Yan, and K. Wu, "Effect of fracture path on the fracture energy of high strength concrete", Cement and Concrete Research., vol. 21, pp. 1601-1606, June 2001.

[3] D. Grady, "Shock equation of state properties of concrete", Structures under Shock and Impact IV, Computational Mechanics, pp.405-414, 1996.
[4] A. A. Bombich, "Development of methods to determine the Hugoniot equation of state of the concrete", Report of Army Engineer Waterways Experiment Station Vicksburg Miss (AD782940), 1974, pp.65-80.

[5] DENNIS Grady, "Impact compression properties of concrete", Proceedings of Sixth International Symposium on Interaction of the Effects of Munitions with Structures, 1993, pp.173-175.

[6] A. Rouabhi, M. Tijani, P. Moser and D. Goetz. "Continuum modelling of dynamic behaviour and fragmentation of quasi-brittle materials: application to rock fragmentation by blasting". International Journal for Numerical and Analytical Methods in Geomechanics. 2005, pp. 729-749.

[7] Q.M. Li, and H. Meng, "About the dynamic strength enhancement of concrete-like materials in a split Hopkinson pressure bar test". International Journal of Solids and Structures, vol. 31, pp.343-360, September 2003.

[8] F. C. Basalo, F. Matta, A. Nanni, "Fiber reinforced cement-based composite system for concrete confinement", Construction and Building Materials, vol. 32, pp. 55-65, June 2011.

(C) Siyi et al.; Licensee Bentham Open.

This is an open access article licensed under the terms of the Creative Commons Attribution Non-Commercial License (http://creativecommons.org/licenses/by-nc/3.0/) which permits unrestricted, non-commercial use, distribution and reproduction in any medium, provided the work is properly cited. 